\title{
PLANO NACIONAL DE QUALIFICAÇÃO DO TRABALHADOR - PLANFOR acertos, limites e desafios vistos do extremo sul
}

Maria da Graça Pinto Bulhões

\begin{abstract}
Resumo: Este artigo considera que o Plano Nacional de Qualificação do Trabalhador - Planfor estabeleceu objetivos gerais ousados: a democratização do acesso à qualificação profissional; a busca de um modelo de desenvolvimento sustentado e uma nova forma de atuação do Estado. Seus acertos concentraram-se no primeiro e terceiro objetivos, enquanto seus limites se fizeram sentir com maior peso no segundo.

Palavras-chave: qualificação profissional; política pública; avaliação de política social.
\end{abstract}

\begin{abstract}
This article considers that the National Plan of Workers' Qualification - Planfor established too audacious general objectives: democratization of access to professional qualification; the search of a sustainable development model; and new State's performance. It also considers that the Plan succeeded in the first and third objectives, while its limits have had great impact on the second one.

Key words: professional qualification; public politics; social politics evaluation.
\end{abstract}

$\mathrm{O}$ Plano Nacional de Qualificação do Trabalhador, implementado em todas as regiões do país a partir de 1996, sob a direção do Ministério do Trabalho e Emprego - MTE e com recursos do Fundo de Amparo ao Trabalhador - FAT, foi uma política pública ousada, que deixou ao novo governo federal, eleito em 2002 , seus principais acertos como herança e seus principais limites como desafios de superação.

Essa constatação baseia-se no trabalho de avaliação externa da implementação do Planfor no Rio Grande do Sul, de 1996 até 2002, que abrangeu a análise do processo de planejamento, gerenciamento e execução das ações de qualificação e, ainda, o exame dos resultados para seus egressos. ${ }^{1}$ Trata-se de uma visão que possui os limites de um olhar focado no espaço regional, portanto, não diretamente generalizável para o conjunto do país, mas que, ao mesmo tempo, possui as vantagens de um trabalho sistemático, contínuo e abrangente, dificilmente realizável no espaço nacional.
A experiência dos encontros com as equipes de avaliação externa do Planfor das diferentes unidades da Federação, ao longo de todo o período, permite afirmar que a análise aqui apresentada pode contribuir para o conhecimento do processo de implementação do plano nas diferentes regiões do país, pois elas viveram, ainda que em intensidades muito diversas, conquistas e pontos de estrangulamento semelhantes.

O Planfor ousou quando se propôs a democratizar o acesso dos trabalhadores à qualificação profissional, principalmente daqueles em situação mais vulnerável no mercado de trabalho, por meio da ampliação de ações de qualificação de natureza pública e gratuita.

O Planfor ousou, ainda, quando se propôs a democratizar o acesso à qualificação profissional de forma articulada à busca de um modelo de desenvolvimento sustentado para o país, em um período de reestruturação produtiva, visando: contribuir para a obtenção de trabalho e geração de renda, a permanência no mercado de trabalho e a ele- 
vação da produtividade, da competitividade e da renda dos trabalhadores; e responder a novas exigências de qualificação, que vão além do "saber-fazer" relacionado ao treinamento para operações específicas.

O Planfor ousou, finalmente, ao propor que os objetivos acima fossem atingidos por meio de uma nova forma de atuação do Estado, caracterizada pela descentralização e o estabelecimento de parcerias com a sociedade civil, capazes de garantir: a participação dos atores sociais interessados nas decisões sobre a qualificação a ser desenvolvida, principalmente dos não-governamentais e locais; o desempenho, pelo governo, do papel de articulador e fomentador de políticas gerais.

Nesse conjunto de objetivos, os acertos concentraramse no primeiro e terceiro blocos: a democratização do acesso à qualificação profissional e a construção de uma nova forma de atuação do Estado; enquanto os limites foram mais fortes no segundo bloco: a articulação com a busca de um modelo de desenvolvimento sustentado para o país.

\section{AMPLIANDO O ACESSO À QUALIFICAÇÃO PROFISSIONAL}

O objetivo geral do Planfor foi apresentar oferta de educação profissional suficiente para qualificar ou requalificar, anualmente, a partir de 1999, pelo menos $20 \%$ da População Economicamente Ativa - PEA, como resultado de suas ações, articuladas ao conjunto de ações das agências de educação profissional já existentes no país.

No Rio Grande do Sul, em 1999, o total de matrículas em instituições de educação profissional cadastradas pelo Ministério da Educação - MEC (1999), somado ao total de inscrições proporcionadas pelo Planfor, representou $6,8 \%$ da PEA - dado provavelmente subestimado pela ausência de informações sobre alunos de instituições não cadastradas pelo MEC. Se, por um lado, a meta não foi alcançada, por outro, o Planfor, além de expandir a oferta de matrículas, responsabilizando-se por $42 \%$ delas, o fez gratuitamente, reconfigurando o acesso à qualificação, uma vez que, no conjunto de instituições cadastradas pelo MEC, $84 \%$ das matrículas eram de instituições privadas.

A ampliação do acesso à qualificação profissional foi garantida à PEA-RS em geral, mas principalmente aos segmentos de trabalhadores considerados pelo Planfor como mais vulneráveis no mercado de trabalho, os quais tiveram, no período 1996-2001, participação nos cursos de qualificação do plano, superior à sua representação na
PEA-RS: desempregados; trabalhadores com renda familiar per capita até um salário mínimo; mulheres; jovens (16 a 24 anos); população não-branca.

O mesmo diferencial de participação apresentaram os indivíduos com inserção precária no mercado de traba1ho, ${ }^{2}$ que no período 1996-2000 exibiram média de participação nos cursos superior à registrada na PEA-RS. Limitações ocorreram, no entanto, na incorporação de trabalhadores com 45 anos ou mais e daqueles com baixa escolaridade (até a quarta série incompleta e de quarta a oitava série incompleta), os quais tiveram taxa de participação nos cursos inferior à de sua representação na PEARS no mesmo período.

\section{ENFRENTANDO OS LIMITES DO DESENVOLVIMENTO DO PAÍS}

Com o objetivo de se articular à busca de um modelo de desenvolvimento sustentável para o Brasil, o Planfor propôs que as ações de qualificação e requalificação profissional fossem definidas em consonância com eixos estratégicos de desenvolvimento do país, dos Estados e dos municípios e, ainda, levando em conta as potencialidades dos mercados de trabalho regionais ou locais. Essas seriam condições necessárias para propiciar a permanência, inserção ou reinserção da PEA no mercado de trabalho, ampliando também sua oportunidade de geração de renda.

As dificuldades de realização desses objetivos expressaram-se, no Rio Grande do Sul, por meio dos seguintes indicadores: no período de 1996 a 1999, verificou-se a ausência de documentação com diretrizes gerais de atuação do governo estadual durante o processo de construção do plano, de fato alterado em 2000 e 2001, ainda que não se tenham indicações da utilização desses documentos pelos parceiros do gestor estadual do Planfor nos municípios; no período 1996-2001, mais de 50\% dos documentos com propostas de cursos, enviados pelos municípios ao gestor estadual, não contavam com um diagnóstico do mercado de trabalho local, apesar de solicitado, anualmente, por este gestor.

Observando-se apenas a Região Metropolitana de Porto Alegre - RMPA, ${ }^{3}$ a capacidade dos municípios de identificarem as potencialidades do mercado de trabalho local mostrou-se razoável: em 2000 e 2001, aproximadamente $60 \%$ das vagas ofertadas em cursos que preparavam para uma ocupação específica tinham clara associação com alguma das 30 ocupações identificadas como mais impor- 
tantes e/ou com maior expansão, as quais, em conjunto, correspondiam a cerca de $55 \%$ do total de ocupados na Região Metropolitana. Na medida, porém, em que os documentos com solicitações de cursos dos municípios da Região Metropolitana, comparativamente com os do interior do Estado, apresentaram um nível superior de informações sobre a realidade do mercado de trabalho local, é possível formular a hipótese de que, no conjunto do Estado, a capacidade de identificar as potencialidades do mercado de trabalho local seja bem mais reduzida, pela insuficiência de fontes de informação.

Ultrapassando essa dificuldade e com peso decisivo sobre as condições de inserção dos trabalhadores, os estudos sobre o mercado de trabalho no país, na década de 90 , indicaram um quadro desfavorável, com o aumento da taxa de desemprego e, principalmente, com o crescimento de formas de inserção ocupacional precárias ${ }^{4}$ (CACCIAMALI, 1999). Esse quadro foi diretamente influenciado pelas baixas e instáveis taxas de crescimento do PIB, bem como pela reestruturação produtiva, que trouxe difusão de inovações tecnológicas e mudanças organizacionais, como a terceirização, diminuição de níveis hierárquicos e alterações em estruturas técnicas e administrativas, que implicaram redução da ocupação e favoreceram a flexibilização das relações de trabalho.

Diante desse quadro desfavorável, o comportamento dos egressos dos cursos do Planfor pode ser considerado

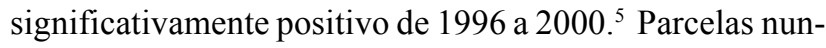
ca inferiores a $40 \%$ daqueles que se encontravam na condição de desempregados quando da realização dos cursos obtiveram ocupação após seu término e, dentre esses, expressivo grupo (que variou de $45,7 \%$, em 1999, a 56,0\%, em 1996) se inseriu em ocupações consideradas de qualidade: assalariamento com carteira assinada no setor privado e assalariamento no setor público. Além disso, entre aqueles que se encontravam ocupados durante os cursos, a maioria (variando de 78,3\%, em 1997, a 88,1\%, em 2000) manteve-se ocupada após o curso.

Mais significativo, ainda, foi o fato de que os porcentuais de ocupação entre aqueles que estavam desempregados durante os cursos foi maior para alguns segmentos mais vulneráveis no mercado de trabalho do que para a média geral dos egressos: mulheres, jovens até 24 anos e não-brancos. Além disso, entre esses segmentos, a elevação de rendimentos do trabalho, após os cursos, foi superior àquela verificada no conjunto dos egressos, ainda que, de forma geral, tenha ocorrido em níveis bastante modestos, inferiores à obtenção de ocupação.
Os benefícios dos egressos dos cursos do Planfor, em termos de inserção no mercado de trabalho, não foram associados diretamente aos cursos pela maioria deles: dentre os que conseguiram ocupação após freqüentar os cursos em 2000 (ano em que o perfil socioeconômico dos alunos se aproximou mais da população-alvo do Planfor, em comparação aos anos anteriores), apenas cerca de $25 \%$ consideraram os cursos como fator mais importante para a obtenção do trabalho. Porém, se somados àqueles que apontaram o fato de ter realizado mais de um curso de qualificação como item mais importante na obtenção de ocupação, a qualificação profissional passa a se constituir no fator mais valorizado, com 33,18\% das respostas, seguida pela experiência profissional, com 30,15\%. No período 1996-1998, os cursos do Planfor foram indicados como fator mais importante por mais de $40 \%$ dos egressos.

Outros dados indicam, ainda, a importância dada à qualificação profissional por aqueles que buscam inserção no mercado de trabalho: entre os egressos dos cursos do Planfor, no período 1996-2000, em torno de 50\% já haviam realizado algum curso de qualificação antes do plano e aproximadamente $17 \%$ passaram por outra qualificação após a do Planfor. Além disso, mais de 95\% de$\operatorname{les}^{6}$ declararam interesse em realizar um novo curso do plano.

Em uma conjuntura de elevado desemprego, a inserção no mercado de trabalho dos egressos provavelmente está ligada a um perfil de trabalhador que investe no aumento dos recursos capazes de facilitar sua ocupação como a qualificação profissional - e que apresenta, sem dúvidas, a maior escolaridade. De fato, observou-se que os alunos do plano, no período 1996-2001, apresentaram escolaridade superior à esperada: a maioria possuía o ensino fundamental completo ou mais (entre 52,5\%, em 2001, e 70,4\%, em 1998), em patamares sempre superiores aos verificados na PEA-RS, que, em 2001, foi de $44,3 \%$.

A qualificação profissional que a maioria dos trabalhadores consegue obter, em sua busca por recursos que facilitem a inserção no mercado de trabalho, caracterizase como cursos básicos, de duração variável, sem regulamentação curricular e sem pré-requisito de escolaridade, em geral pagos. Em 1999, no Rio Grande do Sul, 71,4\% das matrículas em instituições de educação profissional equivaliam a cursos básicos; dessas, 93,0\% eram de instituições privadas (MEC, 1999). Tratam-se, portanto, de cursos abertos à maior parte da PEA-RS, que, como foi indicado, não possui o ensino fundamental completo. 
Esse tipo de formação, no entanto, vem sendo questionada por estudiosos da educação profissional, como insuficiente para responder, hoje, às necessidades da produção e da formação profissional dos trabalhadores. Um posicionamento favorável do país na economia mundial depende, em grande parte, da capacidade de basear a competitividade de sua produção na valorização e na qualificação da força de trabalho e não no uso intensivo de mão-de-obra barata e pouco qualificada (LEITE; POSTHUMA, 19967 ).

Nessa perspectiva, novos requisitos educacionais estão sendo mais valorizados, como os conhecimentos gerais em detrimento dos específicos e a capacidade de raciocínio em detrimento das habilidades manuais (LEITE; POSTHUMA, 1996, p. 71). As novas exigências, no entanto, não se apresentam de forma homogênea para o conjunto da força laboral, em razão da divisão existente no mercado de trabalho, quer no interior das empresas, quer no interior das cadeias produtivas (LEITE; POSTHUMA, 1996, p. 68).

$\mathrm{O}$ acesso e a qualidade do ensino profissional são, portanto, diferenciados. A fórmula tradicional, no país, constitui-se na oferta de cursos de qualificação de duração variável, centrados exclusivamente no treinamento específico, que não contribuem para a elevação do nível de escolaridade dos trabalhadores (SALM; FOGAÇA, 1998, p. 6). Essa formação, além de defasada em relação às novas exigências referidas, é fornecida majoritariamente por instituições privadas, como foi visto.

\section{QUALIFICAÇÃO PROFISSIONAL PÚBLICA E GRATUITA: ALIGEIRADA PARA ALGUNS, DE QUALIDADE E INOVADORA PARA OUTROS}

Levando em conta as novas exigências de qualificação e considerando, ainda, a educação profissional como um instrumento para o desenvolvimento da cidadania de uma força de trabalho que, no país, majoritariamente não possuía mais do que quatro anos de escolaridade básica e tinha poucas chances de voltar à escola, o Planfor propôsse a desenvolver, pelas ações de qualificação, habilidades básicas, específicas e de gestão. ${ }^{8}$ A melhoria de competências básicas e a elevação de escolaridade foram propostas por meio de treinamento de habilidades básicas em cursos de qualificação stricto sensu e, ainda, de cursos de alfabetização e supletivos de ensinos fundamental e médio no âmbito do Planfor.

No Rio Grande do Sul, a edição de $2000^{9}$ envolveu dois tipos de cursos: os isolados, em geral ações pontuais voltadas primordialmente para a qualificação stricto sensu, com uma carga horária média reduzida, que concentraram a maioria dos alunos; os projetos, em geral congregando ações de qualificação profissional (cursos ou outras modalidades) articuladas entre si, que se organizaram em torno de objetivos, metodologias ou seqüências de ações voltadas para o atendimento das necessidades de parcelas específicas da população, dentre os quais incluíram-se, por exemplo, cursos supletivos de ensino fundamental.

No conjunto do plano, os cursos isolados concentraram $85,7 \%$ dos alunos, 58,8\% da carga horária e 50,3\% dos recursos financeiros disponíveis para os cursos, enquanto os projetos ficaram com $14,3 \%$ dos alunos, $41,2 \%$ da carga horária e $49,7 \%$ dos recursos financeiros. Os cursos isolados tiveram carga horária total média de 65,3 horas - abaixo, portanto, de padrões internacionais (100 horas $)^{10}$, das quais 50,8 horas em média corresponderam ao desenvolvimento de habilidades específicas, restando 10,1 horas e 4,4 horas em média, respectivamente, para habilidades básicas e de gestão.

A maior parte dos alunos dos cursos isolados $(53,8 \%)$ avaliou o tempo total do curso como insuficiente ou muito curto e $49,6 \%$ dos estudantes considerou curto ou insuficiente o tempo para o desenvolvimento das habilidades específicas. Entre os alunos dos cursos de projetos, ${ }^{11} \mathrm{o}$ tempo total do curso foi considerado insatisfatório ou muito curto por $28,3 \%$, mas, da mesma forma que nos cursos isolados, a maior crítica foi ao tempo reduzido para o desenvolvimento das habilidades específicas. Na condição de egressos, os alunos de 2000 apontaram como principal deficiência o pouco tempo dedicado para as atividades práticas, independentemente da carga horária do curso freqüentado e da escolaridade dos egressos.

Os conteúdos desenvolvidos, por sua vez, foram considerados como suficientes para o exercício do trabalho por $55 \%$ dos egressos de 2000 que estavam ocupados e avaliaram os cursos. ${ }^{12}$ Um estudo dos cursos da área industrial ofertados pelo Planfor em 1997, realizado por especialista, ${ }^{13}$ indicou que 53\% deles estavam em nível similar ao do Sistema S, usado como parâmetro, considerando a suficiência de carga horária e de conteúdos propostos.

$\mathrm{Na}$ opinião dos professores do Planfor de 2000 - em sua maior parte com formação de nível superior ou médio e experiência na área contemplada pelo curso - o maior problema enfrentado em seu trabalho foi a heterogeneidade das turmas, no que se refere à formação e experiência dos alunos. Articulada à principal crítica feita pelos alunos - tempo total e para atividades práticas reduzidos 
- pode-se concluir que houve dificuldade de ir além das noções gerais sobre os conteúdos tratados, o que foi verificado pela equipe de avaliação externa, em estudos de casos do plano de 1997.

Se para aproximadamente metade dos alunos de 2000 a qualificação desenvolvida - centrada no aprimoramento de habilidades específicas - foi considerada ligeira, para outros ela representou a possibilidade de acesso a uma educação profissional inovadora, o que ocorreu tanto nos cursos isolados quanto nos projetos. Porém, entre estes, verificouse, mais do que nos cursos isolados, a presença de: diversas habilidades; variedade de ações pedagógicas; encaminhamento ao mercado de trabalho por meio do apoio e da capacitação para organização de cooperativas; e, ainda, a proposição de ações de constituição de formadores.

Do total de 26 projetos, considerando os diferentes objetivos explicitados, ${ }^{14} 18$ visavam à profissionalização stricto sensu, isto é, o preparo para uma ocupação específica; 1 voltava-se para informática; 3 para gestão e administração; 9 para cooperativismo; 16 para elevação de escolaridade; 5 para cidadania; 1 para saúde e 1 para meio ambiente.

Dentre os projetos, dois destacaram-se na busca de elevação dos conhecimentos básicos dos alunos: o Projeto Integrar, que associou o Ensino Fundamental supletivo com a qualificação profissional, e o Projeto Serviço Civil Voluntário, voltado para jovens de ambos os sexos, que associou o desenvolvimento de habilidades básicas, específicas e de gestão, ainda que não constituísse um curso supletivo. Ambos foram analisados separadamente dos demais pela equipe de avaliação externa, por solicitação do gestor estadual do Planfor. ${ }^{15}$

A maior inovação presente nos projetos não leva, necessariamente, à conclusão de que cursos isolados sejam ruins. Em 2000, a duração dos cursos ${ }^{16}$ não alterou de forma significativa a avaliação dos alunos sobre vários itens relativos à sua qualidade. Além disso, freqüentadores de projetos, ainda que em menor proporção que os de cursos isolados, também criticaram o tempo reduzido dedicado ao desenvolvimento de habilidades específicas, como foi indicado.

Os projetos e seu grau de inovação, no entanto, acarretaram um custo alto para o plano. Por exemplo, enquanto o conjunto de projetos que articularam elevação de escolaridade básica e qualificação profissional atendeu $7 \%$ dos alunos com $36 \%$ dos recursos financeiros, os cursos isolados com carga horária de até 60 horas abrangeram 59\% dos alunos, com $16 \%$ dos recursos.
Os cursos de menor ou de maior duração podem responder a necessidades diferenciadas de parcelas também diferenciadas dos trabalhadores, cujas condições de inserção no mercado de trabalho dependem, por um lado, do conjunto de recursos de que dispõem, entre os quais se inclui, por exemplo, o nível de escolaridade, e, por outro, do movimento do próprio mercado, em que certas atividades econômicas apresentam maior expansão ou retração de oportunidades.

Dentre os egressos de 2000, o melhor desempenho, na inserção/reinserção no mercado de trabalho ou na manutenção da ocupação, ocorreu entre os ex-alunos dos cursos de curta duração (até 60 horas). Os melhores resultados, em termos de obtenção de ocupação por desempregados e inativos, foram obtidos por aqueles com ensino fundamental completo e pelos da área de vendas.

Em contrapartida, o desempenho dos egressos do Projeto Integrar, em termos de decréscimo do desemprego após o curso, foi inferior ao do conjunto dos alunos do plano, ${ }^{17}$ o mesmo ocorrendo com os do Projeto Serviço Civil Voluntário. ${ }^{18}$ Ao mesmo tempo, porém, uma parcela muito maior de ex-alunos desses dois projetos, comparativamente ao conjunto de egressos do Planfor, considerou que o curso possibilitou-lhes entender melhor a realidade do país e desenvolver-se mais como pessoa.

A qualificação profissional, isoladamente, não garante ocupação. Para muitos daqueles que não têm formação anterior ou experiência na área, os cursos do Planfor voltados para ocupações específicas, em geral curtos, significaram muito pouco, mais um curso, na tentativa frustrada de obter trabalho (FRANZOI, 2003, p. 197).

Essa situação, quando tomada como característica geral do plano, levou muitos de seus críticos a considerá-lo como a venda de uma ilusão de inserção profissional, pelo governo federal, em um difícil momento do mercado de trabalho. Tal crítica, centrada na desproporção entre os altos patamares de desemprego e as medidas governamentais tomadas para combatê-lo, acabou, no entanto, por desconsiderar os ganhos obtidos por importante parcela dos alunos.

Neste momento de retração da ocupação, acentuaramse os critérios seletivos da população trabalhadora, dando origem a camadas sociais que competem em condições desiguais para a obtenção dos (poucos) postos disponibilizados (LIEDKE, 2002). A qualificação tornou-se um dos recursos nessa difícil busca, obtida, muitas vezes, fora da área específica de formação do trabalhador. A qualificação apresentou uma vinculação mais direta com a ocu- 
pação conseguida ou mantida após os cursos para aproximadamente a metade dos egressos ocupados, na maior parte do período 1996-2000, computados aí aqueles que tinham trabalho principal ou trabalho complementar na área do curso e também aqueles que não trabalhavam na área, mas utilizavam os conhecimentos adquiridos nos cursos como apoio ou auxílio na profissão.

$\mathrm{Na}$ difícil conjuntura do mercado de trabalho nos anos 90, a atuação do Estado tornou-se urgente. Atrasado em relação aos países desenvolvidos, o governo passou a implementar políticas públicas de emprego de forma mais abrangente, fazendo-o, porém, em um quadro de fortes restrições financeiras.

\section{EM BUSCA DE UMA NOVA FORMA DE ATUAÇÃO DO ESTADO}

A política de estabilização da economia e de integração à ordem econômico-financeira internacionais, gerou um ajustamento recessivo com impactos negativos sobre o mercado de trabalho e o gasto social do governo. Nesse quadro restritivo, em que a descentralização tornou-se um recurso para a implementação de políticas sociais, ${ }^{19} \mathrm{o}$ Planfor propôs atingir seus objetivos por meio de uma nova forma de atuação governamental, caracterizada pela descentralização e pelo estabelecimento de parcerias com a sociedade civil, de forma que seu papel seria o de articular e fomentar políticas gerais.

O Planfor transferiu a todos os governos estaduais a gestão da maior parte de suas ações de qualificação profissional, ${ }^{20}$ alocando, também, os recursos necessários, provenientes do FAT. Ampliando a participação nas decisões além do âmbito governamental, o Planfor seguiu as diretrizes do Conselho Deliberativo do Fundo, o Codefat (composto, de forma paritária, por representantes nacionais de trabalhadores, empregadores e governo), orientando os governos estaduais a submeterem as propostas de ações de qualificação à aprovação das comissões estaduais de emprego, também tripartites e paritárias.

Além disso, o Planfor estabeleceu a diretriz de que os governos estaduais mobilizassem e orientassem parceiros locais, governamentais e não-governamentais, para a definição das ações e também para a sua execução.

No Rio Grande do Sul, no período 1996-2001, o gestor estadual do Planfor ampliou permanentemente o número de entidades mobilizadas em todo o Estado, principalmente as não-governamentais e locais, para a definição das ações a serem desenvolvidas. Em 1996 e em 1997, o número total de entidades que solicitaram cursos, independentemente de terem sido atendidas, chegou, respectivamente, a 140 e 165 . Entre 1998 e 2001, quando as comissões municipais de emprego tornaram-se responsáveis pela escolha da maior parte das ações de qualificação, esse número aumentou muito. Nesses anos, considerando apenas amostras representativas dos municípios que solicitaram cursos e computadas somente as solicitações aceitas, ${ }^{21}$ o número de entidades partiu de 233 e finalizou o período em 322. Para se ter uma idéia do número de entidades mobilizadas, este resultado se refere a 70 municípios, num total de 461 que participaram da escolha de cursos em 2001.

Entre 1996 e 2001, inverteu-se o espaço ocupado por entidades governamentais e não-governamentais no processo de identificação das ações de qualificação a serem realizadas: de $72,9 \%$ das entidades que solicitaram cursos em 1996, as entidades governamentais passaram a $31,1 \%$ em 2001.

Nesse mesmo ano, do total de entidades que solicitaram cursos, 12,4\% foram de empregadores; $17,7 \%$ de trabalhadores e $38,8 \%$ outras entidades da sociedade civil, de caráter não-sindical. A participação deste último tipo de entidade, voltada para segmentos específicos da população, como, por exemplo, associações de bairro ou de pessoas portadoras de deficiências, tornou-se importante na medida em que cerca de $60 \%$ dos trabalhadores do país encontram-se no mercado informal de trabalho, portanto, sem representação sindical e sem condições de comporem as comissões municipais de emprego, o mesmo valendo para os desempregados.

O gestor estadual do Planfor, no período 1996-2001, ampliou não apenas o número de entidades mobilizadas, como também seu espaço de participação nas decisões. Em 1996, apenas o gestor estadual do Planfor foi responsável pela definição dos cursos; a partir de 1997, aproximadamente $70 \%$ dos recursos do plano destinados aos $\operatorname{cursos}^{22}$ tiveram sua alocação definida com auxílio de parceiros. Em 1997, participaram mais de 80 entidades, distribuídas em 17 mesas de negociação. Em 1998, as Comissões Municipais de Emprego se tornaram a instância de decisão sobre a maior parte dos cursos. Nesse ano, 230 comissões se integraram ao planejamento dos cursos, número que chegou a 391, em 2001.23

Nesse processo de ampliação da participação nas decisões, o plano passou da ausência de parceiros de abrangência municipal, em 1996, para o predomínio destes, em 2001: nas reuniões para escolha final dos cursos nos 
municípios (abertas à participação de entidades que não compunham a comissão, por orientação do gestor estadual), 72,1\% das entidades presentes eram de abrangência municipal.

Para a execução das ações de qualificação, no período 1996-2001, o gestor estadual do Planfor ampliou o número e diversificou o perfil das entidades contratadas: em 1996, foram apenas cinco entidades, sendo que uma delas - uma universidade - concentrou mais de $80 \%$ das vagas ofertadas no plano; em 2001, foram contratadas 53 entidades e nenhuma delas foi responsável por mais de $18 \%$ das vagas.

Entre 1996 e 2001, no total das entidades contratadas, diminuiu a participação de universidades, de instituições integrantes do sistema S e, a partir de 1999, de associações de empregadores e de fundações de empresas. De 1997 em diante, cresceu o porcentual de ONGs e outras entidades de caráter comunitário, religioso, assistencial e voltadas para o atendimento de portadores de necessidades especiais; aumentou, ainda, a participação de escolas técnicas, de escolas de educação básica, de sindicatos, associações, centrais de trabalhadores e escolas sindicais, estes últimos de forma mais oscilante. A partir de 1999, cooperativas passaram a participar crescentemente do plano.

O gestor estadual do Planfor teve êxito quanto a seu objetivo de mobilizar parceiros, com perfil plural e inserção na realidade local, para a definição das ações de qualificação e, ainda, para sua execução. Porém, teve dificuldades para exercer o papel estratégico de articulador dos diferentes parceiros mobilizados. ${ }^{24}$

No período 1996-2001, em que pesem importantes avanços, como a realização de seminários regionais, o gestor estadual do Planfor enfrentou dificuldades para orientar e capacitar tecnicamente seus parceiros para a fundamentação das escolhas de ações de qualificação nos municípios. Ao longo do tempo, solicitou diagnósticos do mercado de trabalho local, sem fornecer informações e preparo técnico para tal aos parceiros ou o fez de forma insuficiente para elevar significativamente a presença de diagnósticos nos documentos com solicitações de cursos.

Outro obstáculo imposto ao gestor foi a integração, em nível estadual dos três principais eixos do planejamento das ações de qualificação: distribuição das ações por setores econômicos, clientelas prioritárias e espaço territorial. Nos anos em que o gestor estadual priorizou um dos eixos - como, por exemplo, a distribuição territorial por meio das comissões municipais de emprego, a partir de 1998 - os demais eixos ficaram à mercê dos parceiros municipais, que mostraram dificuldades de exercer o seu papel. A dimensão estadual do planejamento não foi assegurada por diretrizes iniciais que orientassem as decisões dos parceiros nem por uma sistematização posterior dessas escolhas que permitisse a correção das eventuais distorções, a partir de uma visão de amplitude estadual.

Articular as entidades executoras dos cursos constituiu, ainda, uma barreira ao gestor. Entre elas encontravam-se tanto entidades com reconhecido domínio técnico em sua área de atuação, mas com pouca tradição de atuação junto a segmentos sociais mais vulneráveis, quanto aquelas com forte inserção junto a estes grupos, mas carentes de uma tradição técnica mais sólida na área da formação profissional.

Finalmente, o gestor estadual teve dificuldade de monitorar a qualidade das ações dessas entidades e, mais além, de consolidar junto com elas os avanços metodológicos, por meio do registro sistemático e da divulgação de experiências inovadoras e, também, do estabelecimento de padrões mínimos de carga horária e de conteúdo para as diferentes ações de qualificação, de forma a garantir cursos em níveis diferenciados de complexidade, que permitissem aos alunos continuidade e acúmulo em áreas de conhecimento.

Diante de todas as dificuldades apontadas, observa-se um problema central: os limites do ator governamental para realizar seu papel estratégico. Por um lado, esse ator dispôs de condições privilegiadas, pelo acesso aos resultados estaduais do plano e a recursos técnicos para sua análise - compreendida aí possibilidade de mobilização de diferentes órgãos do governo estadual e também de instituições privadas - e pela disponibilidade de tempo e de profissionais dedicados à gestão do plano - diferentemente das comissões municipais e da comissão estadual de emprego, cuja atuação resulta de trabalho voluntário.

Por outro lado, o ator governamental não estava preparado para exercer o papel que lhe foi conferido. Apesar do visível aperfeiçoamento dos quadros técnicos no período 1996-2001, a política descentralizada, baseada na articulação de diferentes atores ao longo do processo de construção e implementação do plano, exigiu dos técnicos qualificação para atuar em diversas áreas - desde a pedagógica até a econômica, numa posição muito diferente daquela que tradicionalmente lhes era atribuída, de executar orientações do poder central, cuja história se caracterizou por longos períodos de autoritarismo.

Se do ator governamental não era possível exigir a capacidade de responder diretamente a todas as necessida- 
des de seus diferentes tipos de parceiros, o que seria, inclusive, contrário à proposta de descentralização do Planfor, fez-se necessária a capacidade de liderança, de diálogo e de construção de soluções com instituições e recursos humanos capazes de suprir suas lacunas, processo no qual este ator enfrentou limites. Estes, em muitas situações, significaram a transformação da política descentralizada na fragmentação de esforços e na reprodução das desigualdades de condições existentes entre as diferentes realidades locais, deixando o ator governamental de contribuir para compensar tais iniqüidades, bem como de articular e potencializar os resultados dos esforços parciais.

Finalmente, ainda quanto à forma de atuação do Estado, o Planfor estabeleceu a diretriz de que a qualificação profissional fosse integrada a uma política pública de emprego, trabalho e renda, operando de forma articulada com os mecanismos do seguro-desemprego e da intermediação de mão-de-obra.

No Rio Grande do Sul, alguns programas do FAT tiveram um alcance mais efetivo junto aos alunos do plano, comparativamente aos segmentos da PEA que constituem seu público. Em 2000, o número de alunos que se declararam beneficiários do seguro-desemprego correspondeu a 9,8\% do total de classificados como desempregados, num patamar superior ao registrado entre os desempregados da Região Metropolitana de Porto Alegre, de 3,6\% (PED, 2000). Já os alunos que declararam contar com financiamento do programa de geração de emprego e renda equivaliam a 5,5\% do total que se declarou microempresário, trabalhador por conta própria ou dono de negócio familiar, superando o porcentual de beneficiários do Proger/ Urbano em face do total de empregadores e trabalhadores por conta própria no Estado, em 2000, de 1,2\% (PNAD, 1999).

Nesse ano, houve também maior integração entre os programas do FAT na efetivação do plano, como por exemplo a inscrição de treinandos desempregados na intermediação. Não existiu, no entanto, um espaço de atuação conjunta dos gestores responsáveis pelos diferentes programas do FAT, para o planejamento das ações e para sua gestão, elemento fundamental para constituir, efetivamente, um sistema público de emprego.

As dificuldades vividas pelos atores governamentais durante a implementação do Planfor no Rio Grande do Sul fazem parte de um quadro de problemas, cujas dimensões extrapolam o âmbito estadual e, inclusive, nacional e expressam a crise, muito mais profunda, do modelo de desenvolvimento adotado no país a partir dos anos 30 e intensificado no pós-45 - de substituição de importações, com importantes aportes de capital internacional e forte presença do Estado, como diretor do processo e como investidor.

\section{HERANÇAS E DESAFIOS}

A partir da crise econômica internacional iniciada nos anos 70, da reestruturação da economia em curso mundialmente, da globalização econômica, principalmente financeira, e do acirramento da concorrência na economia mundial, num processo de crescente concentração da riqueza (DUPAS, 1999), o Brasil passou a enfrentar, mais do que uma dificuldade conjuntural, a crise do modelo de desenvolvimento que o transformou em um país urbano e industrializado.

Além do problema do crescimento econômico e da intensificação da dependência financeira, o país passou a conviver com a fragilização do Estado Nacional, que, em déficit crescente, tornou-se não só incapaz de realizar os investimentos necessários ao crescimento, como também refém dos órgãos financiadores internacionais na definição de suas políticas. Situação generalizada nos países da América Latina e, no que se refere a limites de ação do Estado Nacional, também vivida, ainda que em intensidade diversa, pelos países desenvolvidos.

Nesse quadro, em 2002, um novo governo federal foi eleito, com a proposta de dirigir o país no processo de construção de um modelo de desenvolvimento econômico mais soberano, dentro da ordem econômica internacional, capaz de estender a amplos segmentos da população brasileira, tradicionalmente excluída, os benefícios do desenvolvimento econômico do país e capaz, ainda, de aprofundar a democracia, articulando às instituições da democracia representativa formas de organização e representação de diferentes segmentos da sociedade brasileira.

Posicionando-se quanto à política pública de qualificação profissional, o novo governo federal instituiu o Plano Nacional de Qualificação - PNQ 2003-2007, ${ }^{25}$ considerando o ano de 2003 como um período de transição, que deveria anteceder a implementação plena do PNQ, a partir de 2004.

O PNQ manteve objetivos em relação aos quais o Planfor foi bem-sucedido. Preservou a posição de se estabelecer uma população-alvo prioritária, composta de segmentos inseridos de forma mais precária no mercado de trabalho, como: trabalhadores sem ocupação; trabalha- 
dores rurais, na condição de agricultores familiares e outras formas de produção familiar; pessoas que trabalham em condição autônoma, por conta própria, cooperativada, associativa ou autogestionada; trabalhadores domésticos, entre outros.

Dentre esses segmentos, o PNQ estabeleceu, ainda, preferência de acesso às pessoas mais vulneráveis economicamente e socialmente, como os trabalhadores com baixa renda e baixa escolaridade e populações mais sujeitas às diversas formas de discriminação social, como desempregados de longa duração, afrodescendentes, indiodescendentes, mulheres, jovens, portadores de deficiência, pessoas com mais de quarenta anos e outras.

O PNQ manteve também a proposta do Planfor de participação de atores governamentais e da sociedade civil na definição das ações de qualificação a serem desenvolvidas, ao apontar para uma demanda atual e futura de qualificação levantada pelo poder público e pela sociedade civil organizada. Ele conservou, ainda, a proposta de participação desses atores na execução dos cursos, ao apontar para a oferta efetiva ou potencial de serviços de entidades públicas ou privadas que podem firmar convênios ou outros instrumentos legais para execução de programas e projetos no âmbito do PNQ. O PNQ manteve, por fim, a participação das comissões estaduais e municipais de emprego.

O PNQ sustentou, ainda que com algumas variações em sua formulação, objetivos enfrentados pelo Planfor com dificuldades, os quais passaram a se constituir, portanto, em desafios de superação:

- a integração com outros programas e projetos financiados pelo FAT, particularmente a intermediação de mãode-obra, o microcrédito, a economia solidária e o segurodesemprego, além de outras políticas públicas que envolvam geração de trabalho, emprego e renda;

- a formação integral (intelectual, técnica, cultural e cidadã) dos trabalhadores brasileiros;

- o aumento da probabilidade de obtenção de emprego e trabalho decente e da participação em processos de geração de trabalho e renda, reduzindo os níveis de desemprego e subemprego;

- a elevação da escolaridade dos trabalhadores, por meio da articulação com as políticas públicas de educação, em particular com a educação de jovens e adultos;

- a inclusão social, a redução da pobreza, o combate à discriminação e a diminuição da vulnerabilidade das populações;
- o aumento da probabilidade de permanência no mercado de trabalho, reduzindo os riscos de demissão e as taxas de rotatividade, ou o aumento da probabilidade de sobrevivência do empreendimento individual e coletivo;

- a elevação da produtividade, a melhoria dos serviços prestados, o aumento da competitividade e das possibilidades de elevação do salário ou da renda.

A manutenção de acertos e a recolocação de desafios repousa em necessidades mais gerais que, segundo estudos e pesquisas na área, se impõem à qualificação profissional:

- o desenvolvimento da capacidade de inovação das empresas, impulsionando a competitividade e o desenvolvimento do país;

- a crescente exigência, por parte das empresas, de uma mão-de-obra mais escolarizada e qualificada;

- a crescente valorização de novos requisitos da força de trabalho, como a iniciativa e prontidão para o contínuo aprendizado;

- diante da desigualdade de acesso dos trabalhadores à qualificação profissional, a implementação de políticas de qualificação voltadas para os segmentos mais excluídos (ALMEIDA, 2003).

Os desafios colocados à política de qualificação profissional fazem parte, na verdade, de outro muito mais amplo que se impõe, hoje, ao país: a construção de um modelo de desenvolvimento com inclusão social e democracia, que o Brasil mostrou, historicamente, enorme dificuldade de consolidar. A política de qualificação profissional não poderá contribuir para este enfrentamento se não se constituir em uma política de massas, que possa, ao mesmo tempo, garantir a qualidade de suas ações.

No Brasil dos anos 90 houve uma reconhecida expansão do acesso ao ensino fundamental, sendo a elevação da qualidade do ensino, hoje, o grande desafio nesse nível de escolaridade. $O$ maior acesso à boa qualificação profissional constitui também um grande desafio, que provavelmente só poderá ser enfrentado pelo governo federal, por meio de uma ampla articulação dos atores envolvidos, somando sua experiência e competência técnica, independentemente das diferenças político-ideológicas. Este é o caminho que se impõe ao governo federal: manter os acertos da gestão anterior e superar seus limites, num claro indicativo de amadurecimento democrático da sociedade brasileira. 


\section{NOTAS}

1. O trabalho de avaliação referido foi realizado por equipe da Universidade Federal do Rio Grande do Sul - UFRGS, de cuja coordenação geral participei durante os anos de 1996, 1997, 1998, 2000 e 2002, sendo consultora nos anos de 1999 e 2001. Atualmente, um grupo de pesquisadores dessa equipe, sob minha coordenação e de Elida R. Liedke, prepara a publicação de um livro, com as diretrizes e os principais resultados do Planfor no Rio Grande do Sul, no período 19962001, e com a metodologia utilizada para a avaliação desses resultados.

2. Considera-se como inserção precária no mercado de trabalho as seguintes posições na ocupação: autônomos; donos de negócio familiar; trabalhadores que costumam realizar seu trabalho de forma eventual (bicos); empregados domésticos; assalariados sem carteira; trabalhadores em autogestão/co-gestão; cooperativados; assentados; trabalhadores não-remunerados; agricultores familiares; trabalhadores na produção para o próprio consumo; trabalhadores na construção para o próprio uso (LIEDKE; BULHÕES, 2002, p. 12).

3. O estudo restringiu-se à RMPA, em razão da disponibilidade de informações relativas ao mercado de trabalho formal e informal nessa área de abrangência, diferentemente do espaço estadual.

4. "Formas de inserção não regidas por contrato de trabalho assalariado típico e (nas quais) as condições de trabalho [...] tendem a um padrão inferior vis-à-vis a condição de assalariado" (GALEAZZI, 2003).

5. A pesquisa de acompanhamento dos egressos dos cursos, no Rio Grande do Sul, foi realizada seguindo orientação do MTE, no que se refere às edições do plano de 1996, 1997, 1998, 1999 e 2000.

6. Exceto para o ano de 1999, em que a taxa foi de $68 \%$.

7. As autoras apontam essa necessidade da indústria brasileira e consideram-na como uma das unanimidades a que a discussão sobre a reestruturação produtiva e a qualificação chegou, em vários países e setores produtivos, após mais de uma década de estudos e pesquisas.

8. Foram consideradas como habilidades básicas: competências e conhecimentos gerais como comunicação verbal e escrita, leitura e compreensão de textos, raciocínio, saúde e segurança no trabalho, preservação ambiental, direitos humanos, informação e orientação profissional e outros eventuais requisitos para as demais habilidades. Como habilidades específicas: competências e conhecimentos relativos a processos, métodos, técnicas, normas, regulamentações, materiais, equipamentos e outros conteúdos específicos das ocupações. Como habilidades de gestão: competências e conhecimentos relativos a atividades de gestão, autogestão, melhoria da qualidade e da produtividade de micro e pequenos estabelecimentos, do trabalho autônomo ou do próprio trabalhador individual, no processo produtivo.

9. No Rio Grande do Sul, no plano de 2000, a equipe de avaliação externa realizou um estudo mais detido e amplo dos cursos, comparativamente aos anos anteriores, razão pela qual se utilizam, aqui, majoritariamente os dados referentes a esse ano. Considera-se, além disso, que a situação dos cursos em 2000, já no final do período de implementação do Planfor no Estado, é expressiva das potencialidades desenvolvidas pelo plano no Rio Grande do Sul. Soma-se a isso o fato de que as grandes tendências verificadas ao longo do tempo em relação aos aspectos aqui tratados mantiveram-se em 2000.

10. O padrão médio internacionalmente aceito para esse tipo de curso encontra-se no patamar de 100 horas (AZEREDO, 1998).

11. Não foi possível calcular a carga horária total média dos projetos, porque a estrutura dos cursos dentro de cada um deles foi composta por diferentes modalidades de ações pedagógicas, invalidando o dado calculado a partir das turmas.

12. Entre os egressos que se encontravam na condição de ocupados, $12,9 \%$ declararam que não sabiam avaliar a suficiência dos conteúdos ensinados.
13. Consultor da equipe de avaliação externa do plano.

14. Em diversos casos, foi atribuído mais de um objetivo ao mesmo curso.

15. A equipe de avaliação externa, ao mesmo tempo em que verificou no Projeto Integrar (cujos cursos foram analisados em 1997) a existência de uma carga horária total bastante inferior à de outros cursos supletivos de mesmo nível de escolaridade, observou uma boa capacidade de manutenção dos alunos no projeto, diferentemente de outros cursos supletivos do sistema público de ensino, que têm significativos índices de evasão.

O Projeto Serviço Civil Voluntário, analisado separadamente dos demais cursos no plano de 2001, já fora indicado, na avaliação de 1999, como um dos projetos que se destacavam por sua capacidade de inovação.

16. A equipe de avaliação externa considerou como curta duração cargas de até 60 horas; média, de 61 a 120 horas e longa, de 121 horas ou mais.

17. Essa análise foi realizada no que se refere aos egressos do Projeto Integrar de 1998, cujos dados são comparados com o conjunto dos exalunos do plano do mesmo ano. Cumpre observar que, entre os freqüentadores do Integrar, foi mais alta a taxa de ocupados e mais baixa a taxa de desempregados, durante o momento de realização dos cursos, comparativamente ao conjunto dos alunos do plano de 1998.

18. Essa análise foi realizada no que se refere aos egressos do Projeto Serviço Civil Voluntário de 2000, cujos dados são comparados com o conjunto dos egressos do plano do mesmo ano. Observa-se que entre os freqüentadores desse projeto foi mais baixa a taxa de ocupados e mais alta a taxa de desempregados, durante o momento de realização dos cursos, comparativamente ao conjunto dos alunos de 2000 .

19. A descentralização das políticas sociais resultou de um processo mais amplo, que envolveu desde as pressões de movimentos democráticos e populares por participação nas decisões até as pressões de órgãos de financiamento internacionais sobre as economias dependentes, não cabendo, nos limites deste trabalho, uma discussão mais aprofundada sobre o tema.

20. Além dessas ações, que, nas unidades da Federação, constituíram Planos Estaduais de Qualificação, compuseram ainda o Planfor as chamadas Parcerias Nacionais ou Regionais, estabelecidas pelo MTE, por meio de convênios com entidades ligadas à educação profissional no país. Parcerias não abordamos neste texto.

21. Nesse período, em face do volume da documentação relativa às entidades que solicitaram cursos nos municípios, a equipe de avaliação externa optou por realizar a análise das entidades pelo estudo da documentação de uma amostra representativa dos municípios.

22. Com exceção do plano de 1999, em que isso ocorreu com menos de $70 \%$ dos recursos.

23. Nos casos em que não existissem Comissões Municipais de Emprego nos municípios, as prefeituras poderiam assumir as funções de decisão: em 1998, participaram do Plano nessa condição 46 prefeituras e, em 2001, 70 prefeituras.

24. Esse tema foi tratado pela autora em artigo referido (BULHÕES, 2002).

25. Considera-se, aqui, para identificar a posição do governo federal no que se refere à política pública de qualificação profissional, o documento intitulado Plano Nacional de Qualificação - PNQ 2003-2007, apresentado pelo MTE, em julho de 2003. Suas diretrizes, aprovadas pelo Codefat, constam da Resolução n ${ }^{\circ} 333 / 2003$ deste conselho. Cumpre observar que não se fez um estudo sistemático dos documentos apresentados, em 2003, pelo MTE, na medida em que não se realizou qualquer trabalho referente à proposta do novo governo federal quanto à política de qualificação. 


\section{REFERÊNCIAS BIBLIOGRÁFICAS}

ALMEIDA, M.L. de. Da formulação à implementação: análise das políticas governamentais de educação profissional no Brasil. Tese (Doutorado) - Instituto de Geociências, Unicamp, Campinas, 2003.

AZEREDO, B. Políticas públicas de emprego: a experiência brasileira. São Paulo: Associação Brasileira de Estudos do Trabalho ABET, 1998, 312 p. (Coleção Teses \& Pesquisas, v. 1).

BULHÕES, M.G.P. Plano Nacional de Qualificação do Trabalhador no Rio Grande do Sul/Brasil: avanços e limites na participação de atores governamentais e não-governamentais. In: MILANI, C.; ARTURI, C.; SOLINÍS, G. (Org.). Democracia e governança mundial: que regulações para o século XXI? Porto Alegre: Ed. Universidade/UFRGS/Unesco, 2002. p. 137-165.

BULHÕES, M.G.P.; LIEDKE, E.R. (Coord.). Avaliação externa do Plano Estadual de Qualificação Profissional do Rio Grande do Sul (PEQ-RS/2000) e Pesquisa de acompanhamento dos egressos (PEQ-RS/1999). Porto Alegre: UFRGS, 2001. (Relatório de pesquisa).

CACCIAMALI, M.C. Desgaste na legislação laboral e ajustamento do mercado de trabalho brasileiro nos anos 90. In: POSTHUMA, A. C. (Org.). Abertura e ajuste do mercado de trabalho no Brasil: políticas para conciliar os desafios de emprego e competitividade. Brasília: OIT e MTE; São Paulo: Ed. 34, 1999. p. 207231.

DRAIBE, S.M. Brasil 1980-2000: proteção e insegurança sociais em tempos difíceis. In: Taller Inter-Regional. Protección Social en una Era Insegura: Un Intercambio Sur-Sur sobre Politicas Sociales Alternativas en Respuesta a la Globalización. Santigo, 14-16 maio 2002. Mimeografado.

DUPAS, G. Economia global e exclusão social: pobreza, emprego, Estado e o futuro do capitalismo. São Paulo: Paz e Terra, 1999. 219 p.

FRANZOI, N.L. Da profissão como profissão de fé ao "mercado em constante mutação”: trajetórias e profissionalização dos alunos do Plano Estadual de Qualificação do Rio Grande do Sul (PEQRS). Tese (Doutorado) - Faculdade de Educação, Unicamp, Campinas, 2003.

GALEAZZI, I. Precarização do trabalho. In: CATTANI, A.D. Dicionário critico sobre trabalho e tecnologia. Petrópolis: Vozes; Porto Alegre: Ed. da UFRGS, 2002. 268 p.

HOLZMANN, L.; PEREIRA, L. Pesquisa de acompanhamento dos egressos (PEQ-RS/2000). Porto Alegre: UFRGS, 2002. (Relatório de pesquisa).

LEITE, M. de P.; POSTHUMA, A.C. Reestruturação produtiva e qualificação: reflexões sobre a experiência brasileira. São Paulo em Perspectiva, São Paulo, Fundação Seade, v. 10, n. 1, p. 63-76, jan./mar. 1996.

LIEDKE, E.R. Reestruturação produtiva e qualificação para o trabalho. In: $4^{\circ}$ CONGRESO LATINOAMERICANO DE SOCIOLOGIA DEL TRABAJO. Havana, set. 2003.

LIEDKE, E.R.; BULHÕES, M.G.P. Sistematização crítica dos resultados da avaliação externa do Plano Estadual de Qualificação Profissional do Rio Grande do Sul (PEQ-RS) 1996-2001. Porto Alegre: UFRGS, 2002. (Relatório de pesquisa).

MINISTÉRIO DA EDUCAÇÃO. Censo da educação profissional. Brasília: 1999.

SALM, C.; FOGAÇA, A. Educação, força de trabalho e competitividade. In: IX FÓRUM NACIONAL - SEMINÁRIO ESPECIAL EDUCAÇÃO, FORÇA DE TRABALHO E COMPETITIVIDADE. Anais, 1998.

Maria da Graça Pinto Bulhões: Professora do Departamento de Sociologia da UFRGS, Membro da equipe de avaliação do Planfor no Rio Grande do Sul, 1996-2002. 